
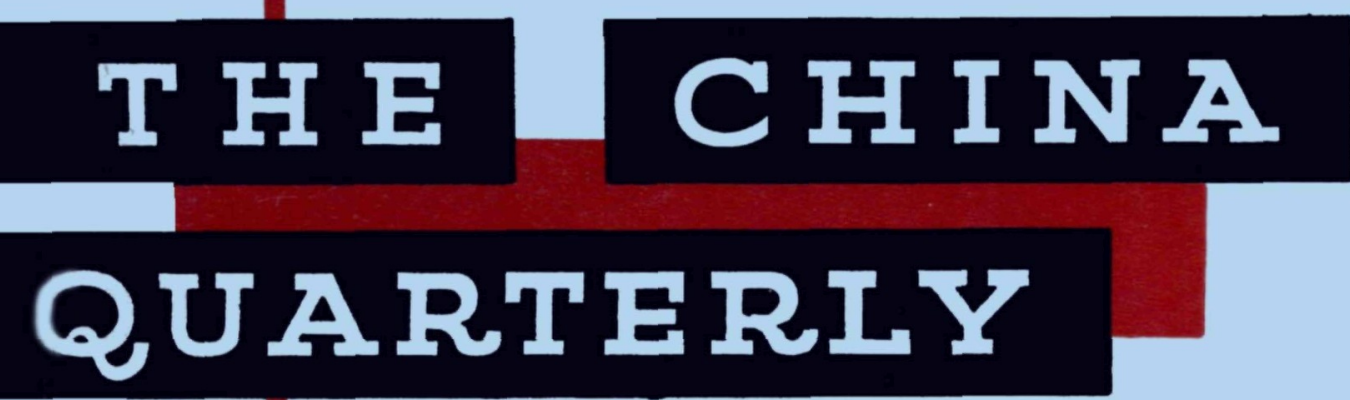

\title{
THE FIRST DECADE
}

APPRAISAL: Howard L. Boorman, C. P. Fitzgerald, G. F. Hudson, Stuart Kirby, Michael Lindsay, Benjamin Schwartz, H. Arthur Steiner, Guy Wint, Karl A. Wittfogel.

ANALYSIS: Economic Development Choh-ming Li The Sino-Soviet Alliance

Robert C. North

China and Asia

Guy Wint

DEBATE: PART I The Legend of "Maoism"

Karl A. Wittfogel

China and Tibet: Background to the Revolt George N. Patterson QUARTERLY CHRONICLE AND DOCUMENTATION

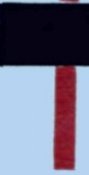

No. I

FIVE SHILLINGS

JAN.-MARCH, 1960 